Article

\title{
Biodegradation of Pyrethroids by a Hydrolyzing Carboxylesterase EstA from Bacillus cereus BCC01
}

\author{
Wei Hu ${ }^{1,2,3, \dagger}$, Qiqi Lu ${ }^{1,2, \dagger}$, Guohua Zhong ${ }^{1,2}$, Meiying $\mathrm{Hu}{ }^{1,2, *}$ and Xin $\mathrm{Yi}^{1,2, *(1)}$ \\ 1 Key Laboratory of Crop Integrated Pest Management in South China, Ministry of Agriculture, South China \\ Agricultural University, Guangzhou 510642, China; weihu2919@163.com (W.H.); qiqiluscau@163.com (Q.L.); \\ guohuazhong@scau.edu.cn (G.Z.) \\ 2 Key Laboratory of Natural Pesticide and Chemical Biology, Ministry of Education, South China Agricultural \\ University, Guangzhou 510642, China \\ 3 National Navel Orange Engineering Research Center, College of Life Sciences, Gannan Normal University, \\ Ganzhou 341000, China \\ * Correspondence: humy@scau.edu.cn (M.H.); yixin2324@scau.edu.cn (X.Y.) \\ + Both authors contributed equally to this work.
}

Received: 21 November 2018; Accepted: 20 January 2019; Published: 30 January 2019

check for updates

Featured Application: (1) The conditions for pyrethroid biodegradation by B. cereus BCC01 were optimized. (2) The biodegradation pathway was analyzed by the identification of metabolites. (3) The key degrading gene est $A$ and related carboxylesterase EstA was characterized. (4) EstA exhibited excellent adaptability under various circumstances.

\begin{abstract}
Microbial degradation has been considered as a rapid, green, and cost-effective technique to reduce insecticide pollutions in a contaminated environment. However, the instability and low efficacy of non-indigenous microorganisms hampers their further exploitation when being introduced into a real environmental matrix. In order to overcome the restriction that these functional microorganisms are under, we investigated the optimal conditions to improve the pyrethroid-degrading ability of one previously isolated bacterium Bacillus cereus BCC01, where $9.6 \%$ of the culture suspension (with cell density adjusted to $\mathrm{OD}_{600}=0.6$ ) was inoculated into $50 \mathrm{~mL}$ media and cultivated at $\mathrm{pH} 8$ and $30{ }^{\circ} \mathrm{C}$, and its metabolic pathway was illuminated by analyzing the main metabolites via gas chromatography mass spectrometry (GC-MS). Most importantly, a key pyrethroid-hydrolyzing carboxylesterase gene est $A$ was identified from the genomic library of strain BCC01, and then expressed in Escherichia coli BL21 (DE3). After purification, the recombinant protein EstA remained soluble, displaying high degrading activity against different pyrethroids and favorable stability over a wide range of temperatures (from $15^{\circ} \mathrm{C}$ to $50^{\circ} \mathrm{C}$ ) and $\mathrm{pH}$ values (6.5-9). Therefore, the EstA-associated biodegradation of pyrethroids was determined, which could provide novel insights to facilitate the practical application of B. cereus BCC01 in the microbial detoxification of pyrethroid contamination.
\end{abstract}

Keywords: pyrethroids; biodegradation; hydrolyzing carboxylesterase; heterologous expression; metabolic pathway

\section{Introduction}

Pyrethroids are a class of synthetic insecticides, their chemical structure mimicked from the natural pyrethrin in Dendranthema plants, consisting of acid and alcohol moieties with an ester bond [1]. It is well-documented that pyrethroids can affect the function of voltage-gated sodium channels by inducing repetitive discharge via prolonged sodium currents [2,3], which are critical for electrical 
signaling in excitable cells. As reported, pyrethroids display negligible acute toxicity to mammals (the $\mathrm{LD}_{50}$ in rats is at $2000 \mathrm{mg} / \mathrm{kg}$ ), but these compounds are highly toxic to target pests, including Lepidoptera (Spodoptera litura Fabricius, Spodoptera exigua Hübner, and Hellula undalis Fabricius) and Diptera (Liriomyza trifolii Burgess and Melanagromyza sojae Zehnter) (the average of $\mathrm{LD}_{50}$ is at $0.45 \mathrm{mg} / \mathrm{kg}$ ) [4-6]. Commercial pyrethroids are mainly applied to control pests in agricultural crops and domestic health. However, they can easily be adsorbed by soil particles and transported via surface runoff, leaching, ground water, and wind drift, thereby causing agricultural nonpoint pollution $[7,8]$. In addition, their high hydrophobicity and persistence due to continuous input may cause residual pollutions in sediment and other ecosystems, posing long-term exposure concerns to non-target organisms via bioaccumulation in food chain $[9,10]$. Most importantly, increasing evidence alarmed the potential neurotoxicity of pyrethroids towards bees and fish, in addition to potential threats to influence reproduction in mammals [11-13], requiring effective techniques to remove pyrethroid contaminations to guarantee environmental safety [14].

In recent decades, a myriad of simple and eco-friendly methods have emerged for cleaning up contaminated environments by employing microorganisms' catalytic ability of hazardous xenobiotic. This approach, known as bioremediation, is generally considered to be less invasive and more restorative of soil functions in removing contaminants from the environment compared to conventional physicochemical methods [15]. As reported, numerous microorganism species have been identified as able to degrade pyrethroid insecticides in polluted soils, including Pseudomonas aeruginosa [16], Steotrophomonas sp. [17], and Serratia marcescens, etc. [18]. However, the degradation performance of these microorganisms is restricted by many factors, including temperature, $\mathrm{pH}$, nutritional conditions, and the impacts of indigenous flora. Therefore, understanding the mechanism that drives the microbial degradation is essential to improve bioremediation techniques. As increasing studies have verified, the functional microorganisms are able to degrade pesticides via hydroxylation, demethylation, dechlorination, dioxygenation, esterification, dehydrochlorination, and oxidation processes. This remarkable degrading property was found to be mediated by the involvement of different enzymes, including laccase, hydrolase, peroxidase, esterase, dehydrogenase, manganese peroxidase, and lignin peroxidase [14,19-21]. By isolating and charactering those functional enzymes, the detailed mechanism of microbial degradation could be determined, from which more information could be acquired to accelerate the actual bioremediation of pyrethroid-contaminated environments.

In this study, we determined the optimal cultivation conditions for one previously identified pyrethroid-degrading strain Bacillus cereus BCC01 by examining the influences of several key effectors on its degradation ability, including temperature, $\mathrm{pH}$ conditions, and initial inoculum [22]. Meanwhile, the microbial degradation pathway was illustrated by analyzing its main degradation products using gas chromatography mass spectrometry (GC-MS). To investigate the mechanism of microbial degradation, we constructed a genomic library and identified gene est $A$ as the key pesticide-degrading enzyme. Then, the purified EstA enzyme was investigated to clarify its substrate specificity to various commonly-used pyrethroids. In addition, the adaptability of the EstA enzyme was furthered examined within a wide range of $\mathrm{pH}$ and temperature conditions, indicating strain BCC01 and its EstA enzyme could be employed as a novel alternative for the bioremediation of pyrethroid-contaminated environments.

\section{Materials and Methods}

\subsection{Chemicals}

Beta-cypermethrin (95\%), delamethrin (98\%), cypermethrin (92.2\%), permethrin (95\%), fenvalerate $(91.2 \%)$ and cyhalothrin (95\%) were obtained from Jiangsu Yangnong Chemical Group Co., Ltd., Yangzhou, Jiangsu, China, and the structural formulas were provided in the Supporting Materials (Table S1). The chemicals were dissolved in acetone at a stock concentration of $10 \mathrm{~g} / \mathrm{L}$, and stored in dark bottles at $4{ }^{\circ} \mathrm{C}$ prior to use. All of the other chemicals and solvents used were of analytical grade. 


\subsection{Strains, Plasmids, and Media}

Beta-cypermethrin-degrading bacteria were previously isolated from a sewage disposal pool at Guangxi Chemistry Institute and identified as B. cereus BCC01 by our group [20]. This strain was stored at $-80^{\circ} \mathrm{C}$ and thawed before use. Escherichia coli DH5 $\alpha$ and E. coli BL21 (DE3) were purchased from Tiangen Biotech (Beijing) Co., Ltd., Beijing, China, and were used as cloning and expression host cells, respectively. The plasmids pUC18 and pET-32a (+) were purchased from Novagon Co., Ltd. and Takara Biomedical Technology Co., Ltd., Beijing, China, and were used as cloning and expression vectors, respectively. For genomic library construction and protein expression, a mineral salt medium (MSM) containing (g/L) $1.0 \mathrm{NH}_{4} \mathrm{NO}_{3}, 0.5 \mathrm{NaCl}, 0.5\left(\mathrm{NH}_{4}\right)_{2} \mathrm{SO}_{4}, 0.5 \mathrm{KH}_{2} \mathrm{PO}_{4}$, and 1.5 $\mathrm{K}_{2} \mathrm{HPO}_{4}$, and Luria-Bertani (LB) medium (g/L) containing 10.0 peptone, 5.0 yeast extract, and 10.0 $\mathrm{NaCl}$ were used. $\mathrm{pH}$ was adjusted by using $10 \% \mathrm{NaOH}$.

\subsection{Optimal Conditions for Beta-Cypermethrin Biodegradation by Strain BCC01}

As reported, BCC01 experienced the lag, exponential, and stationary phases sequentially within $48 \mathrm{~h}$ [22], and the inoculum was cultivated overnight until its optical density (OD) value at $600 \mathrm{~nm}$ $\left(\mathrm{OD}_{600}\right)$ reached to 0.6 (diluted to 10 times when measured). Then the culture suspension was transferred into liquid LB media. After four days of cultivation, $85 \%$ of the added pesticide (initially at $50 \mathrm{mg} / \mathrm{L}$ ) was degraded, which suggested the residual beta-cypermethrin was gradually reduced with the growth of bacteria. To facilitate the process of degradation, optimal conditions for beta-cypermethrin degradation by BCC01 were determined using the response surface method (RSM) based on central composite rotatable design (CCRD), as previously described [23]. Biodegradation may be affected by various conditions, so three parameters that seemed the most probable influencers were selected to investigate the optimal growth conditions for BCC01, including $\mathrm{pH}$, temperature, and inoculum volume. The levels of the three independent variables were designed and listed in a Box-Behnken matrix (Table 1), in which $X_{1}, X_{2}$ and $X_{3}$ represented $\mathrm{pH}$, temperature, and inoculum volume $(v / v)$, respectively. $X_{1}$ refers to $\mathrm{pH}:-1(6), 0(7.5),+1(9) ; X_{1}$ refers to temperature: $-1\left(25^{\circ} \mathrm{C}\right)$, $0\left(30^{\circ} \mathrm{C}\right),+1\left(35^{\circ} \mathrm{C}\right) ; X_{3}$ refers to inoculum: -1 (Inoculum $\left.(\%)(v / v)=5\right), 0($ Inoculum $(\%)(v / v)=10),+1$ (Inoculum $(\%)(v / v)=15)$. Coded levels (at $-1,0$ and 1 ) were used for software model while uncoded levels were the experimental values. For each parameter, coded numbers represented different values. For the measurement of degrading ability, the degradation percentage (\%) of beta-cypermethrin (at initial $100 \mathrm{mg} / \mathrm{L}$ ) was analyzed according to different parameter combinations, and each treatment was repeated three times. Furthermore, degradation percentage (\%) from the designed matrix was employed for regression analyses. The variable values were calculated using the following equation:

$$
x_{i}=\left(X_{i}-X_{0}\right) \Delta X_{i}
$$

where $x_{i}$ is the dimensionless value of an independent variable, $X_{i}$ is the real value of an independent variable, $X_{0}$ is the real value of an independent variable at the center point, and $\Delta X_{i}$ is the step change in the real value of the variable $i$ corresponding to variation by a unit of the three independent variables (Table 1). The analyses were conducted as previously described [24]. Response surface regression was used to analyze the effects on degradation, using Statistical Analysis System (SAS, version 9.0, SAS Institute Inc., Cary, NC, USA) software and the following:

$$
Y_{i}=b_{0}+\sum b_{i} X_{i}+\sum b_{i j} X_{i} X_{j}+\sum b_{i i} X_{i}^{2}
$$

where $Y_{i}$ represented the predicted response, $X_{i}$ and $X_{j}$ are the variables, $b_{0}$ is the constant, $b_{i}$ is the linear coefficient, $b_{i j}$ is the interaction coefficient, and $b_{i i}$ is the quadratic coefficient. 
Table 1. Box-Behnken experimental design matrix and the response of dependent variables for beta-cypermethrin degradation by B. cereus BCC01.

\begin{tabular}{|c|c|c|c|c|c|c|c|}
\hline \multirow{3}{*}{ Run } & \multicolumn{6}{|c|}{ Independent Variables } & \multirow{3}{*}{$\begin{array}{c}\begin{array}{c}\text { Dependent } \\
\text { Variables }\end{array} \\
Y \\
\begin{array}{c}\text { Degradation } \\
(\%)\end{array}\end{array}$} \\
\hline & \multicolumn{3}{|c|}{ Coded Levels } & \multicolumn{3}{|c|}{ Uncoded Levels } & \\
\hline & $X_{1}{ }^{a}$ & $X_{2}^{b}$ & $X_{3}{ }^{c}$ & $\mathrm{pH}$ & $\begin{array}{c}\text { Temperature } \\
\left({ }^{\circ} \mathrm{C}\right)\end{array}$ & $\begin{array}{c}\text { Inoculum } \\
(\%)(v / v)\end{array}$ & \\
\hline 1 & -1 & -1 & 0 & 6 & 25 & 10 & $88.9 \pm 3.1 \mathrm{de}$ \\
\hline 2 & -1 & 1 & 0 & 6 & 35 & 10 & $90.6 \pm 2.2 \mathrm{~cd}$ \\
\hline 3 & 1 & -1 & 0 & 9 & 25 & 10 & $94.5 \pm 1.8 \mathrm{ab}$ \\
\hline 4 & 1 & 1 & 0 & 9 & 35 & 10 & $94.8 \pm 1.4 \mathrm{ab}$ \\
\hline 5 & 0 & -1 & -1 & 7.5 & 25 & 5 & $90.7 \pm 2.1 \mathrm{~cd}$ \\
\hline 6 & 0 & -1 & 1 & 7.5 & 25 & 15 & $97.9 \pm 2.3 a$ \\
\hline 7 & 0 & 1 & -1 & 7.5 & 35 & 5 & $92.7 \pm 1.5 b c$ \\
\hline 8 & 0 & 1 & 1 & 7.5 & 35 & 15 & $96.8 \pm 1.5 \mathrm{a}$ \\
\hline 9 & -1 & 0 & -1 & 6 & 30 & 5 & $75.2 \pm 1.6 f$ \\
\hline 10 & 1 & 0 & -1 & 9 & 30 & 5 & $86.6 \pm 1.9 \mathrm{e}$ \\
\hline 11 & -1 & 0 & 1 & 6 & 30 & 15 & $75.8 \pm 1.3 \mathrm{f}$ \\
\hline 12 & 1 & 0 & 1 & 9 & 30 & 15 & $91.3 \pm 1.5 \mathrm{bcd}$ \\
\hline 13 & 0 & 0 & 0 & 7.5 & 30 & 10 & $97.1 \pm 1.8 \mathrm{a}$ \\
\hline 14 & 0 & 0 & 0 & 7.5 & 30 & 10 & $96.5 \pm 3.0 \mathrm{a}$ \\
\hline 15 & 0 & 0 & 0 & 7.5 & 30 & 10 & $96.8 \pm 1.7 \mathrm{a}$ \\
\hline
\end{tabular}

Note: ${ }^{\text {a }}$ refers to $\mathrm{pH}:-1(6), 0(7.5),+1(9) ;{ }^{\mathrm{b}}$ refers to temperature: $-1\left(25^{\circ} \mathrm{C}\right), 0\left(30^{\circ} \mathrm{C}\right),+1\left(35^{\circ} \mathrm{C}\right)$; and ${ }^{\mathrm{c}}$ refers to inoculum: -1 (Inoculum $(\%)(v / v)=5), 0$ (Inoculum $(\%)(v / v)=10),+1$ (Inoculum $(\%)(v / v)=15)$. The data presented are means of three replicates with standard deviation, which is within $5 \%$ of the mean. Different letters indicate significant differences $(p<0.05$, LSD test).

\subsection{Growth of Strain BCC01 in Beta-Cypermethrin-Supplemented Media}

An individual colony was cultivated in solid LB media without shaking. Inocula were prepared by inoculating an individual colony into $30 \mathrm{~mL}$ LB medium at $30^{\circ} \mathrm{C}$ and $170 \mathrm{rpm}$ on a rotary shaker. After overnight-cultivation, $9.6 \%(v / v 9.6 \% \times 30 \mathrm{~mL})$ of this suspension (inocula) was inoculated into $30 \mathrm{~mL}$ of LB media. Then the growth experiment was performed in LB liquid medium with or without beta-cypermethrin at $30^{\circ} \mathrm{C}$ and $170 \mathrm{rpm}$ on a rotary shaker. Samples $(100 \mu \mathrm{L}$ for one time) were collected periodically from the $30 \mathrm{~mL}$ culture suspensions to measure the $\mathrm{OD}_{600}$, using a spectrophotometer (100 $\mu \mathrm{L}$ for one time) and to determine the beta-cypermethrin concentration by high-performance liquid chromatography (HPLC) at different intervals ( $3 \mathrm{~mL}$ for each interval), including cultivating after 20 h, 40 h, 60 h, 80 h, 100 h, and 120 h, respectively. And the experiment was performed in triplicate. The HPLC analysis was referred to the aforementioned process [25]. The samples were analyzed on an Agilent 1200 HPLC (Agilent, Santa Clara, CA, USA) equipped with a Kromasil C18 reversed phase column $(5 \mu \mathrm{m} \times 4.6 \mathrm{~mm} \times 250 \mathrm{~mm})$. The mobile phase was methanol, acetonitrile, and water (v:v:v, 58:18:24) at $1 \mathrm{~mL} / \mathrm{min}$ and $20^{\circ} \mathrm{C}$ with $10 \mu \mathrm{L}$ injection volume. The beta-cypermethrin was detected at a wavelength of $235 \mathrm{~nm}$. Good linearity was obtained within beta-cypermethrin concentrations ranging from 5 to $100 \mathrm{mg} / \mathrm{L}$. The limit of detection (LOD) was determined as the lowest concentration giving a response three times greater than the signal-to-noise $(\mathrm{S} / \mathrm{N})$ ratio. The limit of quantitation (LOQ) was estimated as 10 times of the $\mathrm{S} / \mathrm{N}$ ratio [26]. The LOD and LOQ of beta-cypermethrin reached to $0.2 \mu \mathrm{g} / \mathrm{mL}$ and $0.7 \mu \mathrm{g} / \mathrm{mL}$, respectively.

\subsection{Identification of Metabolites and Degradation Pathway}

The potential metabolic products formed during beta-cypermethrin biodegradation were analyzed by GC-MS. Culture filtrates were collected at different intervals while incubating strain BC001 in spiked pyrethroid, and filtrate extraction and clean-up procedures were conducted as previously reported [27]. Briefly, the liquid cultures were mixed with $2 \% \mathrm{NaCl}$ and $0.5 \mathrm{~mol} / \mathrm{L} \mathrm{HCl}$, and then $10 \mathrm{~mL}$ dichloromethane was added. The aqueous and organic phases were separated via centrifugation. 
The organic phase was evaporated to near dryness and the residue was dissolved in $10 \mathrm{~mL}$ methanol. Finally, the extracts were filtered through a $0.45 \mu \mathrm{m}$ membrane filter and stored at $4{ }^{\circ} \mathrm{C}$ before examination. Intermediates were identified by using an HP-5 MS capillary column $(30.0 \mathrm{~m} \times 250 \mu \mathrm{m}$ $\times 0.25 \mu \mathrm{m}$ ) with array detection from $30-500 \mathrm{~nm}$ (total scan). The operating conditions were as follows: the column was held at $90^{\circ} \mathrm{C}$ for $2 \mathrm{~min}$, ramped at $6{ }^{\circ} \mathrm{C} / \mathrm{min}$ to $150{ }^{\circ} \mathrm{C}$ (first ramp), held at $150{ }^{\circ} \mathrm{C}$ for $10 \mathrm{~min}$, ramped at $10^{\circ} \mathrm{C} / \mathrm{min}$ to $180^{\circ} \mathrm{C}$ (second ramp), held at $180^{\circ} \mathrm{C}$ for $3 \mathrm{~min}$, and finally ramped at $20{ }^{\circ} \mathrm{C} / \mathrm{min}$ to $260{ }^{\circ} \mathrm{C}$ (third ramp), then held at $260^{\circ} \mathrm{C}$ for $10 \mathrm{~min}$. The temperature for the transfer line was $280^{\circ} \mathrm{C}$, and the ionization energy was $70 \mathrm{eV}$. The injection volume was $1 \mu \mathrm{L}$ without splitting at $250{ }^{\circ} \mathrm{C}$. Helium was used as a carrier gas at a flow rate of $1.0 \mathrm{~mL} / \mathrm{min}$. The identification process was repeated three times to improve accuracy. Compounds were identified by comparison of the mass spectrum of each peak with those of authentic standards in a mass spectra library (NIST, 2010) and literature.

\subsection{Genomic Library Construction and Screening}

Genomic DNA extraction was conducted using a DNA-isolation kit from Takara Biomedical Technology Co., Ltd., Beijing, China, according to the manufacturer's instructions. To construct a size-fractionated genomic library, genomic DNA of BCC01 was partially digested with Sau3A I. DNA fragments from 1 to $10 \mathrm{~kb}$ were pooled and ligated into the pUC18 plasmid vector that had been previously digested with BamH-I. Recombinant plasmids were used to transform competent cells of E. coli DH5 by plating on Isopropyl-D-thiogalactoside/X-gal indicator plates containing $100 \mu \mathrm{g} / \mathrm{mL}$ ampicillin. The recombinants were screened by transferring all positive colony (white) onto MSM/LB $(v: v, 9: 1)$ agar plates with high concentration of beta-cypermethrin (at $500 \mathrm{mg} / \mathrm{L}$ ) and ampicillin, as previous described $[28,29]$. The colonies that survived the high concentration of beta-cypermethrin screening in the first round were transferred and cultivated in liquid LB culture media with $100 \mathrm{mg} / \mathrm{L}$ beta-cypermethrin and ampicillin to examine the degrading ability of beta-cypermethrin in a second screening. Finally, they were then transferred to LB liquid media and cultivated at $37^{\circ} \mathrm{C}$ for $8 \mathrm{~h}$.

\subsection{Sequence Analysis}

The target recombinant plasmid was extracted and then sequenced by Invitrogen Biotechnology Co., Ltd. (New York, CA, USA) by using M13 primers (M13F: TGTAAAACGACGGCCAGT, M13R: CAGGAAACAGCTATGACC) [30]. The open reading frame (ORF) of the identified gene was analyzed using the ORF Finder online tool at http:/ / www.ncbi.nlm.nih.gov/gorf/gorf.html. The homology of nucleotide and protein sequence was detected using the BLAST program at NCBI (http:/ /blast.ncbi. nlm.nih.gov/Blast.cgi). The ExPASy ProtParam Server was harnessed to analyze the amino acids and physical properties at http:/ / web.expasy.org/protparam. To classify proteins, the Pfam database and the Conserved Domain Search Service (CD Search) were employed.

\subsection{Expression and Purification of Esterase EstA}

The complete ORF of the identified est $A$ was amplified by PCR (Peltier Thermal Cycler, Bio-Rad, Hercules, CA, USA) using primers EstA-F (5'-GGGGTACCATGATGAAATTAGCATCTCC- ${ }^{\prime}{ }^{\prime}, \mathrm{Kp} n$ $I$ (the restriction site is underlined) and EstA-R (5'-CCCTCGAGTTACCAATCTAGTTGCTCC- ${ }^{\prime}$, Xho I restriction site was underlined) based on the est $A$ sequence. The amplified product was digested with KpnI and XhoI and ligated into the KpnI and XhoI sites of pET32a (+), resulting in the recombinant plasmid pET32a-estA. The culture, induction, and harvest of recombinant $E$. coli BL21 (DE3) cells carrying pET32a-est $A$ were performed according to the standard method [31]. The positive clone was identified by PCR, and after IPTG $(1 \mathrm{mmol} / \mathrm{L})$ was added, those positive colonies were inoculated overnight until its $\mathrm{OD}_{600}$ reached $0.4-0.6$. The culture suspensions were broken by sonic oscillator and examined by SDS-PAGE. After expression, the recombinant protein was purified using a Ni-Agarose His Kit (CWbiotech, Shanghai, China), according to the manufacturer's instructions. Briefly, the cultures were harvested by centrifugation and lysed with solution (10 mM imidazole, 
$300 \mathrm{mM} \mathrm{NaCl}$ and $50 \mathrm{mM} \mathrm{NaH}_{2} \mathrm{PO}_{4}$ ). The protein solution was washed and balance by binding buffer in the kit $\left(20 \mathrm{mM} \mathrm{NaH}_{2} \mathrm{PO}_{4}, 500 \mathrm{mM} \mathrm{NaCl}, \mathrm{pH}\right.$ 7.8) to make sure the sample adhered to the column completely after putting the filtered solution into the column. Then, a linear gradient concentration of imidazole was used to elute the recombinant protein adhered on the column, and then purified protein was dialyzed by Tris-HCL ( $\mathrm{pH}=7.4$ ). His-tag was removed by incubating in Bovine Enterokinase overnight. The purified protein was analyzed via $1.5 \%$ sodium dodecyl sulfate polyacrylamide gel electrophoresis (SDS-PAGE). Protein concentrations were measured using the Bradford method with standard bovine serum albumin (BSA) [32].

\subsection{Substrate Specificity Assay}

Ten $\mu \mathrm{L}$ purified EstA and $0.5 \mathrm{~mL}$ PBS were added to $1.5 \mathrm{~mL}$ Eppendorf tubes. Beta-cypermethrin, cypermethrin, fenvalerate, deltamethrin, cyhalothrin, and permethrin were individually spiked in EstA solution at $20 \mathrm{mg} / \mathrm{L}$ (in PBS) and homogenized by using vortexes. All tubes were incubated in a $30^{\circ} \mathrm{C}$ of water bath for $2 \mathrm{~h}$, which was set as the optimal condition of esterase activity reported previously [33]. Then the residual pesticides were extracted by using acetonitrile and ultrasonic for $20 \mathrm{~min}$. The residual substrates were quantified by HPLC as previously mentioned to indicate the substrate activity of EstA. Each measurement for each group was repeated three times.

\subsection{Effects of Temperature and pH on Enzyme Activity}

Beta-cypermethrin was spiked at $20 \mathrm{mg} / \mathrm{L}$ into $0.5 \mathrm{~mL}$ PBS with $10 \mu \mathrm{L}$ purified EstA in $1.5 \mathrm{~mL}$ Eppendorf tubes. After homogenization, each mixture was placed into a $15^{\circ} \mathrm{C}, 20^{\circ} \mathrm{C}, 30^{\circ} \mathrm{C}, 35^{\circ} \mathrm{C}$, $40^{\circ} \mathrm{C}, 45^{\circ} \mathrm{C}$, or $50^{\circ} \mathrm{C}$ water bath for $2 \mathrm{~h}$. The residual levels of beta-cypermethrin were determined by HPLC, as previously described. Further, $0.5 \mathrm{~mL}$ spiked EstA solution was adjusted to $\mathrm{pH}$ 5.0, 5.5, 6.0, 6.5, 7.0, 7.5, 8.0, 9.0, and 9.5 and incubated in a $30^{\circ} \mathrm{C}$ water bath for $2 \mathrm{~h}$. The activity of degrading enzyme, which was defined as the dosage of EstA enzyme used to degrade $1 \mu \mathrm{g}$ beta-cypermethrin per minute $(\mu \mathrm{g} / \mathrm{min})$, was detected and calculated to analyze its ability against various $\mathrm{pH}$ values and temperatures as follows:

$$
\mathrm{A}=\frac{m \times V}{T \times W},
$$

where $A$ is the enzyme activity $(\mathrm{U}), m$ represents the concentration of beta-cypermethrin after treatment determined by HPLC $(\mu \mathrm{g} / \mathrm{L}), V$ is the total reaction volume $(\mathrm{L}), T$ is the reaction time (min), and $W$ is the enzyme volume $(\mathrm{mL})$.

\subsection{Statistical Analysis}

Standard deviations were determined using the SAS software packages. The significance $(p<$ 0.05 ) of differences was determined by one- or two-way analysis of variance (ANOVA) and evaluated by post-hoc comparison of means using the least significant difference test.

\section{Results and Discussion}

\subsection{Optimization of Culture Conditions for Beta-Cypermethrin Degradation by Strain BCC01}

The degrading abilities of $B$. cereus BCC01 under different culture conditions are presented in Table 1 . The data were analyzed using a response surface regression procedure as the following predicted quadratic polynomial equation:

$$
\begin{aligned}
& Y=98.2914+5.78545 X_{1}-0.012575 X_{2}-0.98936 X_{3}-7.582225 X_{1}^{2}-0.36935 X_{1} X_{2} \\
& +1.855 X_{1} X_{3}+1.489975 X_{2}^{2}-0.20375 X_{2} X_{3}-2.107075 X_{3}^{2}
\end{aligned}
$$

where $Y$ represents the predicted degradation percentage (\%), and $X_{1}, X_{2}$ and $X_{3}$ are the values for $\mathrm{pH}$, temperature and inoculum volume, respectively. Further, the ANOVA results of the fitted model are 
shown in Table S2, where the data suggested that $\mathrm{pH}\left(X_{1}\right)$ and inoculum volume $\left(X_{3}\right)$ had a significant influence on beta-cypermethrin degradation activity, while the effect of temperature $\left(X_{2}\right)$ was smaller. To establish a reliable model for the CCRD experiment, only statistically significant factors $(p<0.05)$ were included in the model, that is, a first order effect $\left(X_{2}, X_{3}\right)$, and three interaction effects $\left(X_{1} X_{2}\right.$, $\left.X_{2} X_{2}, X_{2} X_{3}\right)$ were not significant $(p>0.05)$ and were removed from the model, so that the effects of inoculum volume and $\mathrm{pH}$ on biodegradation were found in a three-dimensional response surface with fixed temperature (the non-significant variable) at the coded " 0 " level $\left(30^{\circ} \mathrm{C}\right)$ (Figure 1$)$. The model predicted maximum biodegradation $(99.4 \%)$ at the stationary point, where the optimum codes for $X_{1}$ and $X_{3}$ were 0.37143 and 0.07346 . After being translated, the uncoded values were $\mathrm{pH}$ at 8 and inoculum volume at $9.6 \%$. Therefore, the optimal conditions for beta-cypermethrin degradation by strain $\mathrm{BCC} 01$ were to be produced by inoculating $9.6 \%$ inocula at $\mathrm{pH} 8$ at $30^{\circ} \mathrm{C}$. Applying the deduced parameters to the medium with beta-cypermethrin at an initial $100 \mathrm{mg} / \mathrm{L}$, the biodegradation by strain BCC01 reached $99.6 \%$ after five days of incubation, which was consistent with the predicted degradation $(99.4 \%)$, demonstrating a reliable model. Such a method to optimize the culture condition has been generally accepted and widely used in many studies $[27,34,35]$.
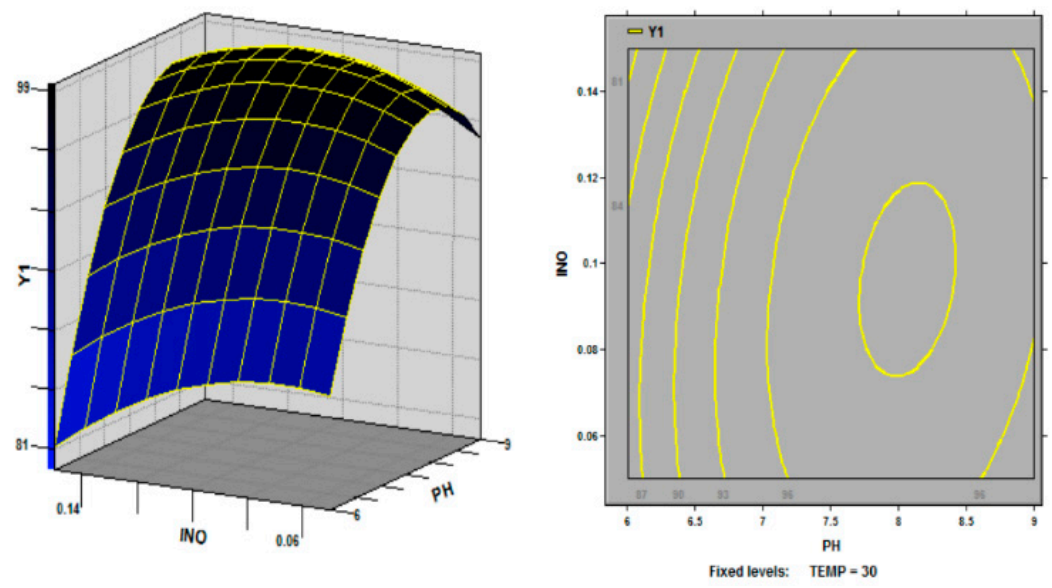

Figure 1. Three-dimensional response of the effects of $\mathrm{pH}\left(X_{1}\right)$ and inoculum volume $\left(X_{3}\right)$ on the degradation $(Y)$ of beta-cypermethrin by BCC01.

\subsection{Bacterial Growth and Degradation of Beta-Cypermethrin}

The average recovery of fortified beta-cypermethrin in LB medium was $105.3 \%$ with $4.0 \%$ of relatively standard deviation (RSD), showing the HPLC method applied was acceptable to quantify the concentration of beta-cypermethrin for following experiments. After optimization, the bacterial growth was monitored by measuring the $\mathrm{OD}_{600}$ value of $\mathrm{BCC} 01$ in LB medium. In Figure 2, BCC01 showed normal growth and entered the logarithmic phase after inoculation without an obvious lag phase. Its growth reached a stationary phase at $40 \mathrm{~h}$ after inoculation and began to decline after $70 \mathrm{~h}$. In beta-cypermethrin spiked cultures, the growth of BCC01 was slightly slower at the beginning of incubation than it was in the pure LB medium (Figure 2A). After a certain period of adjustment, the conditions could be recovered to be favorable enough for bacterial growth. By monitoring the growth of strain BCC01 and quantifying the residual beta-cypermethrin concentrations at different intervals, we found that the added pyrethroid was rapidly degraded within logarithmic phase. When the growth of $\mathrm{BCC} 01$ reached at the stationary period, the degradation of beta-cypermethrin slowed down (Figure 2B), suggesting the pyrethroid-degrading ability of BCC01 was closely related to the tendency of bacterial proliferation. 
A

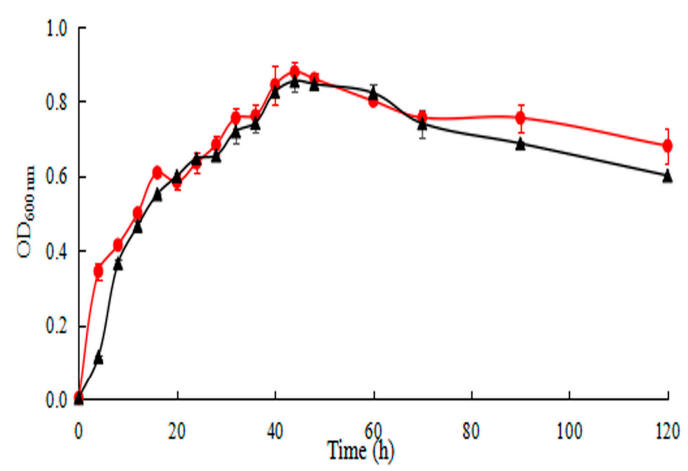

B

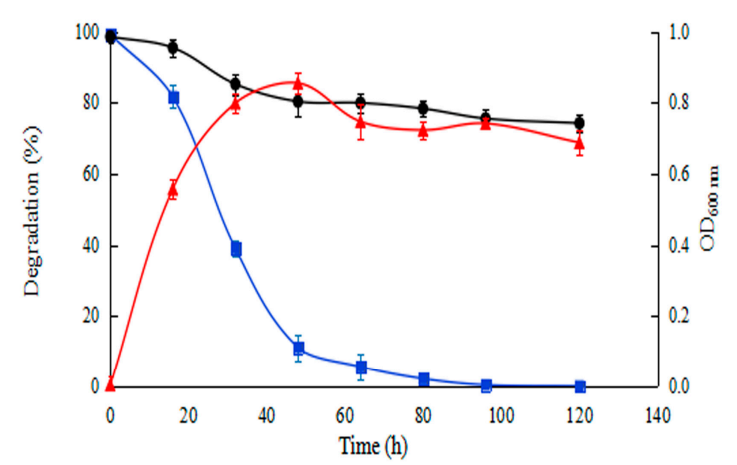

Figure 2. The growth of Bacillus cereus BCC01 and degradation of beta-cypermethrin. (A) The growth curves of strain BCC01. •, LB media; $\mathbf{\Lambda}$, with $100 \mathrm{mg} / \mathrm{L}$ Beta-cypermethrin in LB media. (B) Bacterial growth and related degradation of beta-cypermethrin. $\bullet$, beta-cypermethrin control without bacteria; $\boldsymbol{\Lambda}$, growth in $100 \mathrm{mg} / \mathrm{L}$ beta-cypermethrin; and $\mathbf{\square}$, degradation of beta-cypermethrin with Bacillus cereus BCC01.

\subsection{Metabolic Products during Degradation}

The metabolic products of beta-cypermethrin in BCC01-involved degradation were detected by GC-MS. As shown in Figure S1, six by-products were identified as $\alpha$-hydroxy-3-phenoxy-benzeneacetonitrile, 3-phenoxybenzaldehyde, methyl-3-phenoxybenzoate, 3,5-dihydroxybenzoic acid, 3,4-dihydroxybenzoic acid, and 3,5-dimethoxyphenol. After five days, the parent compound and its metabolites were hardly detected, showing that strain BCC01 decomposed beta-cypermethrin entirely into chemicals with simple structures. According to the metabolites obtained, a potential degradation pathway for the degradation of beta-cypermethrin by BCC01 was devised (Figure 3). In it, $\alpha$-hydroxy-3-phenoxy-benzeneacetonitrile and permethric acid were the first products to come through the cleavage of the ester linkage of beta-cypermethrin and spontaneously convert into 3-phenoxybenzaldehyde, which is consistent with a previous report [36]. Methyl-3-phenoxybenzoate was formed by the oxidation of 3-phenoxybenzaldehyde and then broken into 3,5-dihydroxybenzoic acid and 3,4-dihydroxybenzoic acid via the ester cleavage. Next, 3,5-dimethoxyphenol was produced as the result of group addition or substitution of 3,5-dihydroxybenzoic, which can be mineralized into $\mathrm{CO}_{2}$ and $\mathrm{H}_{2} \mathrm{O}$. This degradation pathway was slightly different from that reported previously. The different degradation pathways of micro-organisms isolated under different conditions indicated that it is feasible to use micro-organisms from different conditions to degrade different insecticides, and the optimal cultivating condition could be illuminated as the method used in this study.

\subsection{Construction of a Genomic Library and Screening of Degrading Genes}

Pyrethroids are ester-containing compounds. As suggested by the degradation pathway, the cleavage of ester bonds by esterase is the major route of degradation [21]. The genomic library of B. cereus BCC 01 was constructed using cloning vector $\mathrm{PUC} 18$, in which approximately 11,000 clones were generated. After two rounds of screening, one recombinant demonstrated high activity, such that $46.8 \%$ of the spiked beta-cypermethrin was efficiently degraded within five days of incubation, while only $9 \%$ was metabolized in the control, in line with a previous study [30]. The low yield of identification may be partly due to the limit of quality of the genomic library we constructed, the probable unrecognition of regulatory elements from unknown bacteria in E. coli, difficulties of expression in heterologous host or the formation of inclusion bodies and the toxicity of the expressed proteins to hosts [37]. Sequence analysis indicated that the inserted fragment was $1492 \mathrm{bp}$ (accession number: MH588686), containing a 744 bp ORF, and showing a highly conserved domain (with 99\% of similarity) to the reported gene $e s t A$ encoding pyrethroid-hydrolyzing esterase from $B$. cereus E33L 
(accession no., CP009968.1). Therefore, the esterase gene that was screened out from this study was named $e s t A$. Subsequently, bioinformatics analysis indicated that the protein EstA was composed of 247 amino acids and its molecular mass was $28.2 \mathrm{kDa}$ with $\mathrm{pI}$ at 5.2. It displayed as $45.3 \% \alpha$-helix, $15 \% \beta$-sheet, and $39.7 \%$ random coil in its secondary structure (Figure S2). The data further confirmed that there was a conversed domain of esterase/lipase. Compared with multiple esterase sequences, the $\mathrm{Ser}^{94}$ of EstA was located in a highly conserved esterase peptide motif of Gly-X-Ser-X-Gly (Figure S3), forming a concave active center for the biodegradation of beta-cypermethrin, which is a typical feature of the esterase family [38,39]. As reported previously, the carboxylesterase from Brevibacillus sp. strain KB2 and B. cereus strain PU was be able to degrade malathion, and the carboxylesterase gene was cloned $[40,41]$, however, the ability of EstA to degrade pyrethroid pesticide was never reported.

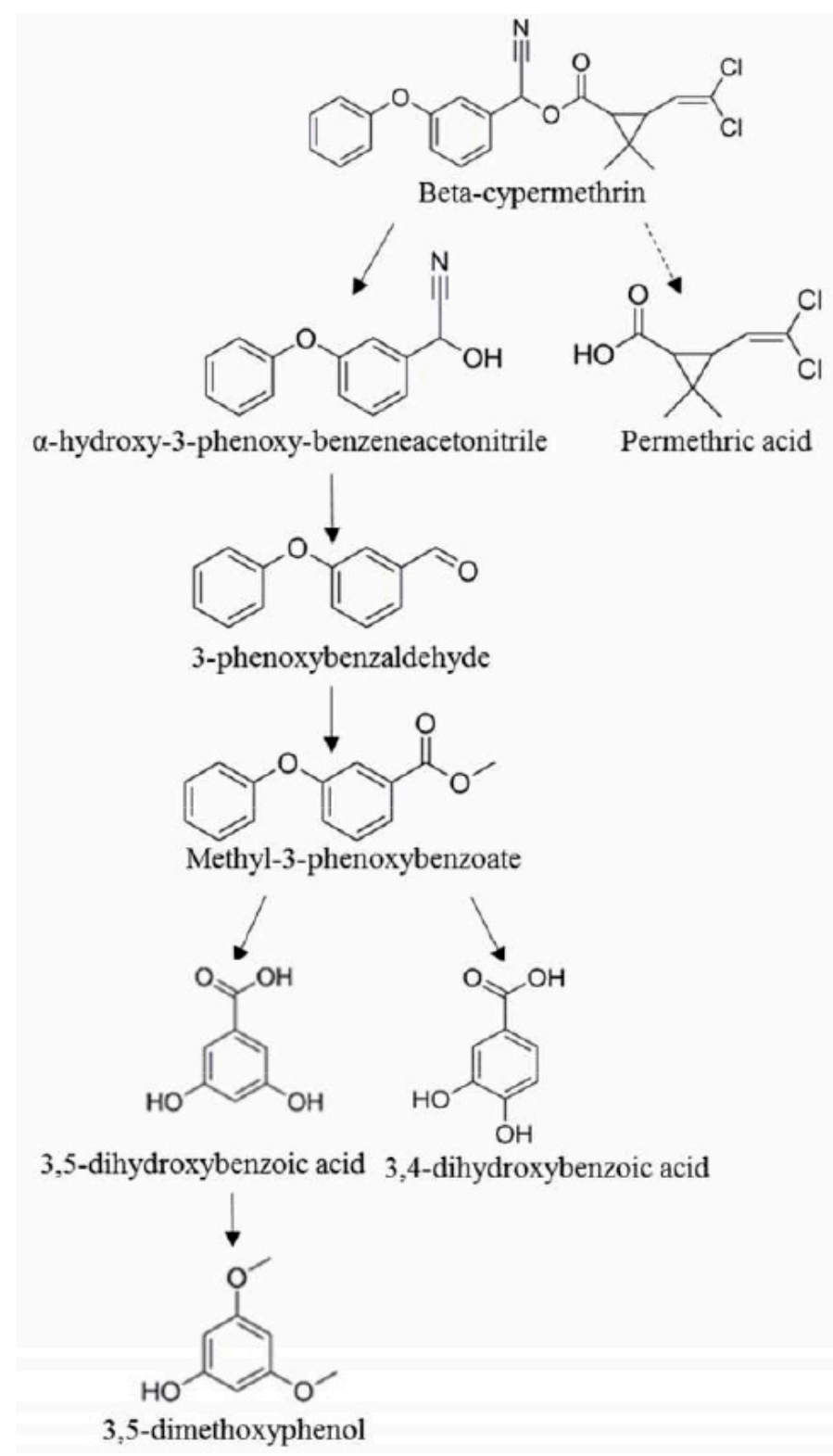

Figure 3. Proposed pathway of beta-cypermethrin through the biodegradation by strain BC001.

\subsection{Expression and Activity of Recombinant EstA}

Recombinant EstA was highly expressed in E. coli BL21 (DE3) using pET-32a (+) with the induction of IPTG at different temperatures (Figure $4 \mathrm{~A}$ ). The fusion protein of BL21/pET-32a-est $A$ cell showed a band at $45 \mathrm{kDa}$, including a $17 \mathrm{kDa}$ label, which is in accordance with the molecular mass deduced 
previously from the amino acid sequence $(28.2 \mathrm{kDa})$ (Figure $4 \mathrm{~A})$. The purified EstA protein exhibited a single band in SDS-PAGE analyses at the same mass of the pre-purified fusion protein shown in Figure 4B. The concentration of purified EstA was determined to be $243.6 \mathrm{mg} / \mathrm{L}$ by using the calibration of optical density and standard a BSA method $(y=0.0005 x+0.2182$, calibrated in Figure S4).

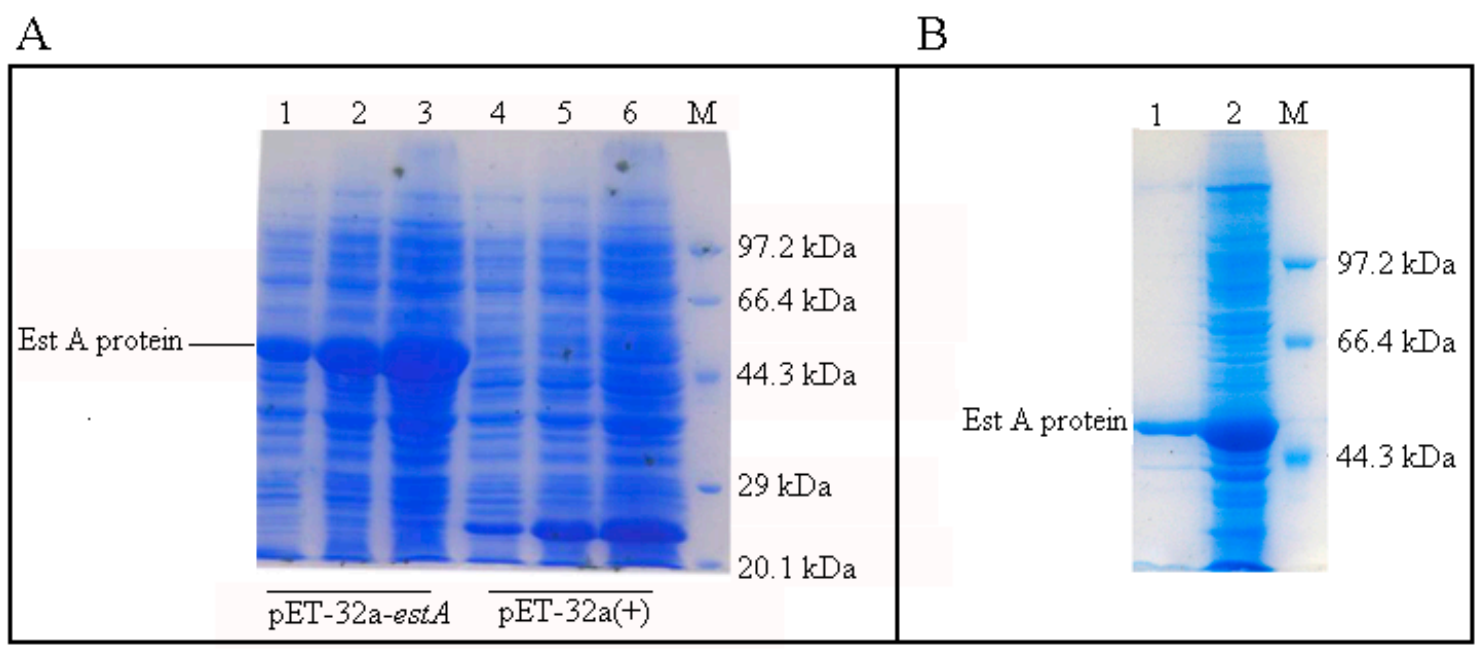

Figure 4. SDS-PAGE analysis of induced protein and its purification protein. (A) SDS-PAGE analysis of induced EstA protein at different temperatures. $\mathrm{M}=$ protein marker (Code No.: 3450, Takara, Dalian, China); lane 1, 2, and 3 = the full cell protein of Escherichia coli BL21/pET-32a-est $A$ induced in $30{ }^{\circ} \mathrm{C}$, $25^{\circ} \mathrm{C}$, and $20^{\circ} \mathrm{C}$; lane 4, 5, and $6=$ the full cell protein of Escherichia coli BL21/pET-32a (+) induced in $30{ }^{\circ} \mathrm{C}, 25^{\circ} \mathrm{C}$, and $20^{\circ} \mathrm{C}$; (B) $\mathrm{M}$ = protein marker; lane $1=$ purified EstA; lane 2 = the full cell protein of Escherichia coli BL21/pET-32a-est $A$ expressed at $20^{\circ} \mathrm{C}$.

\subsection{Degrading Ability of Purified EstA}

To investigate the ability to degrade different pyrethroids, the substrate specificity of EstA was evaluated with six commonly used pyrethroids at an initial $20 \mathrm{mg} / \mathrm{L}$. As shown in Figure 5, after $2 \mathrm{~h}$ of reaction, the degradation of each compound reached to $40.5 \sim 100 \%$, indicating that the purified EstA was a broad-spectrum pyrethroid-hydrolyzing enzyme. This may be because the most pyrethroid pesticides possess a similar ester bond in their molecular structure [21]. As pesticide residues are mixtures in the environment, a broad-spectrum pyrethroid-degrading enzyme would have boarder range in practical application. And as each enzyme has its optimal substrate, in this study, EstA showed the highest degrading ability to beta-cypermethrin, which was considered as $100 \%$ for its enzyme degrading activity and the activity of enzymatic degradation was $7.9 \mathrm{mg} / \mathrm{min}$. The relative enzyme activity to degrade other pyrethroid was normalized to the highest degradation percentage (the activity to degrade beta-cypermethrin, in this case). Compared to a previous study, the enzyme activity in our case exhibited relatively higher activity compared with the enzyme isolated by Zhai et al (3.29 $\mathrm{U}$ for degrading $1 \mathrm{nmol}$ beta-cypermethrin, in this case, and $123.34 \mathrm{U}$ for degrading $1 \mathrm{nmol}$ lambda-cyhalothrin, with $\mathrm{U}$ indicated as the enzyme dosage employed to degrade $1 \mu \mathrm{g}$ of beta-cypermethrin per minute) (cypermethrin: $95.7 \%$, fenvalerate: $85.7 \%$, deltamethrin: $70.4 \%$, cyhalothrin: 55.2\%, and permethrin: 40.5\%) (Figure 5) [36]. 


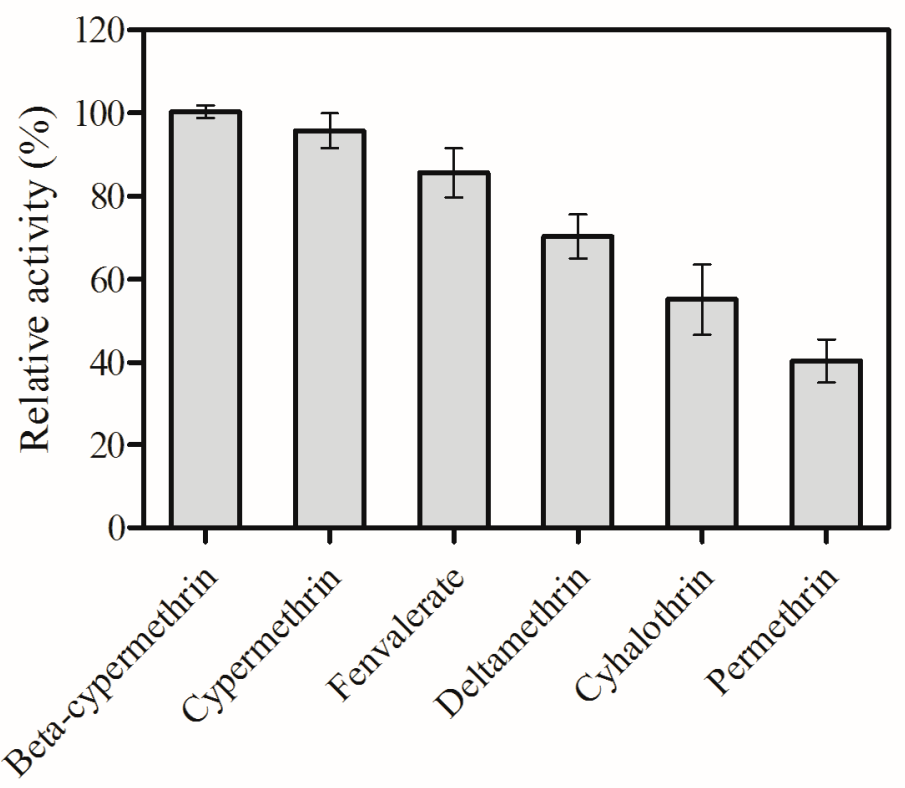

Figure 5. The relative activity of EstA to various pyrethroid insecticides.

Generally, the function of specifically expressed proteins can be easily affected by different external conditions. For providing more information to facilitate the application of the purified enzyme, the tolerance of EstA under wide temperatures was assessed from $15{ }^{\circ} \mathrm{C}$ to $50{ }^{\circ} \mathrm{C}$. As shown in Figure 6A, the optimal temperature for EstA catalysis was $35^{\circ} \mathrm{C}$, and lower or higher temperature could significantly inhibit enzyme activity, since relative activities dropped below $40 \%$ at $15{ }^{\circ} \mathrm{C}$ and $50{ }^{\circ} \mathrm{C}$. Additionally, EstA activity was also determined under various $\mathrm{pH}$ values ranging from $\mathrm{pH} 5.0$ to 9.5 (Figure 6B). These results indicated that EstA preferred neutral and alkaline conditions ( $\mathrm{pH}$ 6.5-9.0) where the enzyme activity of EstA remained above $60 \%$. Maximal enzyme activity was measured at $\mathrm{pH}$ 8. The purified protein of EstA was able to exert degrading function over a wide range of $\mathrm{pH}$ and temperature. This is a very important feature of an organism to be employed for bioremediation in variable environments. The condition in field is very complex and influenced by many factors, and the parameter in laboratory condition could not be introduced directly to the practical application. Still, the optimal cultivation conditions, preferred enzymatic activity, and biodegrading mechanism illustrated in this study could enrich the available biodegrading resources.

A

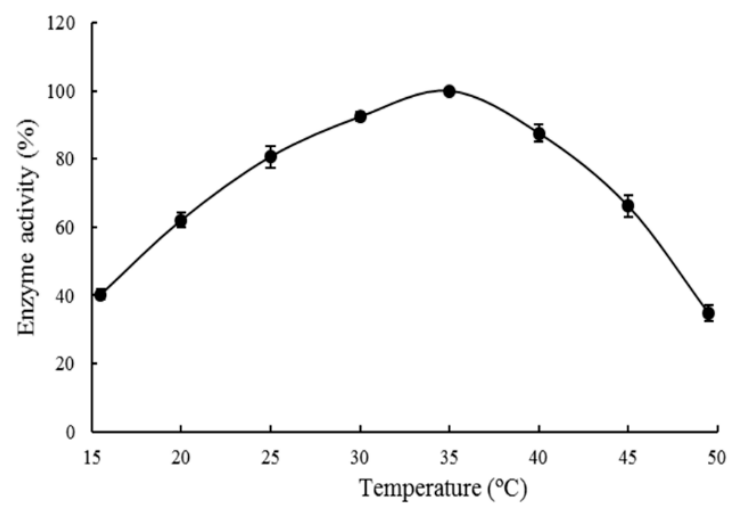

B

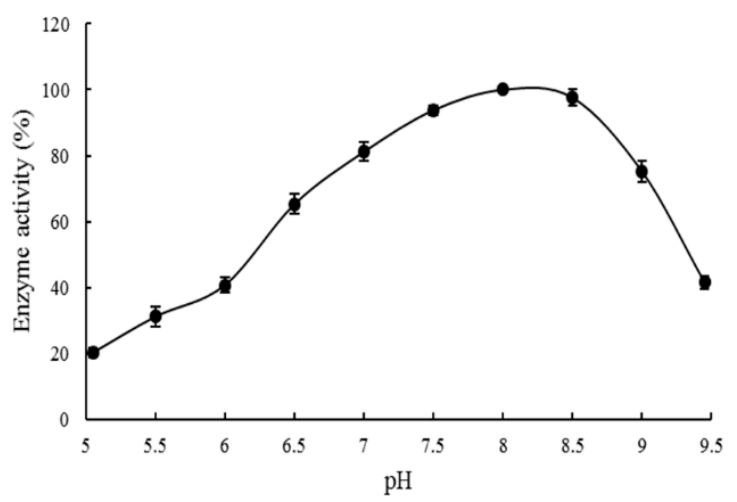

Figure 6. Effects of temperature and $\mathrm{pH}$ on EstA activity. (A) Temperature; (B) $\mathrm{pH}$. 


\section{Conclusions}

We investigated the optimal conditions for pyrethroid degradation by strain BCC01. Additionally, a key pyrethroid-degrading gene est $A$ was cloned and expressed in E. coli BL21 (DE3). The recombinant protein remained soluble, and the purified enzyme displayed broad substrate specificity, high enzyme activity, and favorable stability over a wide range of temperatures and $\mathrm{pH}$ values. All of the results provide better understanding of the microbial degradation of pyrethroids and enrich the resources for the future application.

Supplementary Materials: The following are available online at http:/ /www.mdpi.com/2076-3417/9/3/477/s1, Figure S1: Mass spectra of metabolites from beta-cypermethrin degradation by B. cereus BCC01. Figure S2: The predicted secondary structure of EstA. H: $\alpha$-helix, E: $\beta$-sheet and 39.7\% and C: random coil. Figure S3: Comparison multiple sequences between reported and deduced amino acid sequence of EstA. The conserved motif of "G-X-S-X-G" was boxed. Figure S4: Calibration curve of optical density and protein concentration by Bradford method. Table S1: The structural formulas of the compounds. Table S2: Quadratic polynomial model for degradation by B. cereus BCC01 and its analysis of variance (ANOVA).

Author Contributions: X.Y. contributed to the design of most experiments; W.H. and Q.L. performed the experiments and undertook data evaluation; G.Z. and M.H. participated in designing experiments; and X.Y. wrote the paper.

Funding: This work was supported by a grant from the National Natural Science Foundation of China (No. 31371960), the Guangdong Province Science and Technology Plan Project (No. 2015B020207003), the Natural Science Foundation of Jiangxi Province (20161BAB214178, and 20171BAB214029), and the Key Program of Science and Technology Planning Project of Jiangxi Province (20171BBF60076).

Conflicts of Interest: The authors declare no conflict of interest.

\section{References}

1. Saillenfait, A.-M.; Ndiaye, D.; Sabaté, J.-P. Pyrethroids: Exposure and health effects-An update. Int. J. Hyg. Environ. Health 2015, 218, 281-292. [CrossRef] [PubMed]

2. Narahashi, T. Mode of action of pyrethroids. Bull. World Health Org. 1971, 44, 337-345. [PubMed]

3. Rinkevich, F.D.; Du, Y.; Tolinski, J.; Ueda, A.; Wu, C.-F.; Zhorov, B.S.; Dong, K. Distinct roles of the DmNav and DSC1 channels in the action of DDT and pyrethroids. NeuroToxicology 2015, 47, 99-106. [CrossRef] [PubMed]

4. Soderlund, D.M. Resmethrin, the first modern pyrethroid insecticide. Pest Manag. Sci. 2015, 71, 801-807. [CrossRef] [PubMed]

5. Vargas, G.; Lastra, LA.; Ramirez, G.D.; Solis, M.A. The Diatraea Complex (Lepidoptera: Crambidae) in Colombia's Cauca River Valley. Neotrop. Entomol. 2018, 47, 395-402. [CrossRef] [PubMed]

6. Viviana, M.A.; James, M.-L.; Claudia, E.-R.; Michaudc, J.P.; Germán, V. Host resistance to two parasitoids (Diptera: Tachinidae) helps explain a regional outbreak of novel Diatraea spp. stem borers (Lepidoptera: Crambidae) in Colombia sugarcane. Biol. Control 2019, 129, 18-23.

7. Nørum, U.; Friberg, N.; Jensen, M.R.; Pedersen, J.M.; Bjerregaard, P. Behavioural changes in three species of freshwater macroinvertebrates exposed to the pyrethroid lambda-cyhalothrin: Laboratory and stream microcosm studies. Aquat. Toxicol. 2010, 98, 328-335. [CrossRef] [PubMed]

8. Zhang, C.; Jia, L.; Wang, S.; Qu, J.; Li, K.; Xu, L.; Shi, Y.; Yan, Y. Biodegradation of beta-cypermethrin by two Serratia spp. with different cell surface hydrophobicity. Bioresour. Technol. 2010, 101, 3423-3429. [CrossRef] [PubMed]

9. Farajzadeh, M.A.; Khoshmaram, L.; Nabil, A.A.A. Determination of pyrethroid pesticides residues in vegetable oils using liquid-liquid extraction and dispersive liquid-liquid microextraction followed by gas chromatography-flame ionization detection. J. Food Compos. Anal. 2014, 34, 128-135. [CrossRef]

10. Li, H.; Cheng, F.; Wei, Y.; Lydy, M.J.; You, J. Global occurrence of pyrethroid insecticides in sediment and the associated toxicological effects on benthic invertebrates: An overview. J. Hazardous Mater. 2017, 324, 258-271. [CrossRef] [PubMed]

11. Lao, W.; Tsukada, D.; Greenstein, D.J.; Bay, S.M.; Maruya, K.A. Analysis, occurrence, and toxic potential of pyrethroids, and fipronil in sediments from an urban estuary. Environ. Toxicol. Chem. 2010, 29, 843-851. [CrossRef] [PubMed] 
12. Zhao, M.; Chen, F.; Wang, C.; Zhang, Q.; Gan, J.; Liu, W. Integrative assessment of enantioselectivity in endocrine disruption and immunotoxicity of synthetic pyrethroids. Environ. Pollut. 2010, 158, 1968-1973. [CrossRef] [PubMed]

13. Deng, W.; Yu, L.; Li, X.; Chen, J.; Wang, X.; Deng, Z.; Xiao, Y. Hexafluoroisopropanol-based hydrophobic deep eutectic solvents fordispersive liquid-liquid microextraction of pyrethroids in tea beverages and fruit juices. Food Chem. 2019, 274, 891-899. [CrossRef] [PubMed]

14. Cycoń, M.; Piotrowska-Seget, Z. Pyrethroid-Degrading Microorganisms and Their Potential for the Bioremediation of Contaminated Soils: A Review. Front. Microbiol. 2016, 7, 1463. [CrossRef] [PubMed]

15. Kang, J.-H.; Katayama, Y.; Kondo, F. Biodegradation or metabolism of bisphenol A: From microorganisms to mammals. Toxicology 2006, 217, 81-90. [CrossRef] [PubMed]

16. Zhang, C.; Wang, S.; Yan, Y. Isomerization and biodegradation of beta-cypermethrin by Pseudomonas aeruginosa CH7 with biosurfactant production. Bioresour. Technol. 2011, 102, 7139-7146. [CrossRef] [PubMed]

17. Lin, Q.; Chen, S.; Hu, M.; Haq, M.U.; Yang, L.; Li, H. Biodegradation of cypermethrin by a newly isolated actinomycetes HU-S-01 from wastewater sludge. Int. J. Environ. Sci. Technol. 2011, 8, 45-56. [CrossRef]

18. Cycoń, M.; Żmijowska, A.; Piotrowska-Seget, Z. Enhancement of deltamethrin degradation by soil bioaugmentation with two different strains of Serratia marcescens. Int. J. Environ. Sci. Technol. 2014, 11, 1305-1316. [CrossRef]

19. Liang, W.Q.; Wang, Z.Y.; Li, H.; Wu, P.C.; Hu, J.M.; Luo, N.; Cao, L.X.; Liu, Y.H. Purification and Characterization of a Novel Pyrethroid Hydrolase from Aspergillus niger ZD11. J. Agric. Food Chem. 2005, 53, 7415-7420. [CrossRef]

20. Maqbool, Z.; Hussain, S.; Imran, M.; Mahmood, F.; Shahzad, T.; Ahmed, Z.; Azeem, F.; Muzammil, S. Perspectives of using fungi as bioresource for bioremediation of pesticides in the environment: A critical review. Environ. Sci. Pollut. Res. 2016, 23, 16904-16925. [CrossRef]

21. Sogorb, M.A.; Vilanova, E. Enzymes involved in the detoxification of organophosphorus, carbamate and pyrethroid insecticides through hydrolysis. Toxicol. Lett. 2002, 128, 215-228. [CrossRef]

22. Liu, J.; Hu, M.; Li, Y.; Chen, S.; Lin, H.; Yi, X.; Zhong, G. Isolation and Identification of a Beta-cypermethrin Degrading Strain BCC01. J. Anhui Agric. Sci. 2012, 40, 270-272.

23. Chen, X.; Tang, L.; Li, S.; Liao, L.; Zhang, J.; Mao, Z. Optimization of medium for enhancement of $\varepsilon$-poly-L-lysine production by Streptomyces sp. M-Z18 with glycerol as carbon source. Bioresour. Technol. 2011, 102, 1727-1732. [CrossRef] [PubMed]

24. Zhao, H.-M.; Du, H.; Feng, N.-X.; Xiang, L.; Li, Y.-W.; Li, H.; Cai, Q.-Y.; Mo, C.-H. Biodegradation of di-n-butylphthalate and phthalic acid by a novel Providencia sp. 2D and its stimulation in a compost-amended soil. Biol. Fertil. Soils 2016, 52, 65-76. [CrossRef]

25. Hu, W.; Xie, W.; Chen, S.; Zhang, N.; Zou, Y.; Dong, X.; Rashid, M.; Xiao, Y.; Hu, M.; Zhong, G. Separation of Cis- and Trans-Cypermethrin by Reversed-Phase High-Performance Liquid Chromatography. J. Chromatogr. Sci. 2015, 53, 612-618. [CrossRef] [PubMed]

26. Liu, J.; Morales-Narváez, E.; Vicentd, T.; Merkoçi, A.; Zhong, G. Microorganism-decorated nanocellulose for efficient diuron removal. Chem. Eng. J. 2018, 354, 1083-1091. [CrossRef]

27. Zhao, H.-M.; Du, H.; Lin, J.; Chen, X.-B.; Li, Y.-W.; Li, H.; Cai, Q.-Y.; Mo, C.-H.; Qin, H.-M.; Wong, M.-H. Complete degradation of the endocrine disruptor di-(2-ethylhexyl) phthalate by a novel Agromyces sp. MT-O strain and its application to bioremediation of contaminated soil. Sci. Total Environ. 2016, 562, 170-178. [CrossRef] [PubMed]

28. Khalameyzer, V.; Fischer, I.; Bornscheuer, U.T.; Altenbuchner, J. Screening, Nucleotide Sequence, and Biochemical Characterization of an Esterase from Pseudomonas fluorescens with High Activity towards Lactones. Appl. Environ. Microbiol. 1999, 65, 477-482.

29. Zhai, Y.; Li, K.; Song, J.; Shi, Y.; Yan, Y. Molecular cloning, purification and biochemical characterization of a novel pyrethroid-hydrolyzing carboxylesterase gene from Ochrobactrum anthropi YZ-1. J. Hazard. Mater. 2012, 221-222, 206-212. [CrossRef]

30. Kosugi, S.; Ohashi, Y. E2Ls, E2F-like Repressors of Arabidopsis That Bind to E2F Sites in a Monomeric Form. J. Biol. Chem. 2002, 277, 16553-16558. [CrossRef]

31. Sambrock, J.; Russel, D. Molecular cloning: A laboratory manual, 3rd ed. Immunology 2001, 49, 895-909.

32. Bradford, M.M.A. A Rapid and Sensitive Method for the Quantitation on Microgram Quantities of Protein Utilizing the Principle of Protein-Dye Binding. Anal. Biochem. 1976, 72, 248-254. [CrossRef] 
33. Soror, S.; Verma, V.; Rao, R.; Rasool, S.; Koul, S.; Qazi, G.; Cullum, J. A cold active esterase of Streptomyces coelicolor A3(2): From genome sequence to enzyme activity. J. Ind. Microbiol. Biotechnol. 2007, 34, 525-531. [CrossRef] [PubMed]

34. Dayana Priyadharshini, S.; Bakthavatsalam, A.K. Optimization of phenol degradation by the microalga Chlorella pyrenoidosa using Plackett-Burman Design and Response Surface Methodology. Bioresour. Technol. 2016, 207, 150-156. [CrossRef] [PubMed]

35. Schenone, A.V.; Conte, L.O.; Botta, M.A.; Alfano, O.M. Modeling and optimization of photo-Fenton degradation of 2,4-D using ferrioxalate complex and response surface methodology (RSM). J. Environ. Manag. 2015, 155, 177-183. [CrossRef]

36. Chen, S.; Hu, M.; Liu, J.; Zhong, G.; Yang, L.; Rizwan-ul-Haq, M.; Han, H. Biodegradation of beta-cypermethrin and 3-phenoxybenzoic acid by a novel Ochrobactrum lupini DG-S-01. J. Hazard. Mater. 2011, 187, 433-440. [CrossRef] [PubMed]

37. Li, G.; Wang, K.; Liu, Y.H. Molecular cloning and characterization of a novel pyrethroid-hydrolyzing esterase originating from the Metagenome. Microb. Cell Fact. 2008, 7, 38. [CrossRef] [PubMed]

38. Choi, Y.J.; Miguez, C.B.; Lee, B.H. Characterization and Heterologous Gene Expression of a Novel Esterase from Lactobacillus casei CL96. Appl. Environ. Microbiol. 2004, 70, 3213-3221. [CrossRef] [PubMed]

39. Ruan, Z.; Zhai, Y.; Song, J.; Shi, Y.; Li, K.; Zhao, B.; Yan, Y. Molecular Cloning and Characterization of a Newly Isolated Pyrethroid-Degrading Esterase Gene from a Genomic Library of Ochrobactrum anthropi YZ-1. PLoS ONE 2013, 8, e77329. [CrossRef] [PubMed]

40. Singh, B.; Kaur, J.; Singh, K. Biodegradation of malathion by Brevibacillus sp. strain KB2 and Bacillus cereus strain PU. World J. Microbiol. Biotechnol. 2012, 28, 1133-1141. [CrossRef]

41. Singh, B.; Kaur, J.; Singh, K. Transformation of malathion by Lysinibacillus sp. isolated from soil. Biotechnol. Lett. 2012, 34, 863-867. [CrossRef] [PubMed]

(C) 2019 by the authors. Licensee MDPI, Basel, Switzerland. This article is an open access article distributed under the terms and conditions of the Creative Commons Attribution (CC BY) license (http:/ / creativecommons.org/licenses/by/4.0/). 